\section{Visión Electrónica \\ Más que un estado sólido}

http: revistas.udistrital.edu.co/ojs/index.php/visele/index

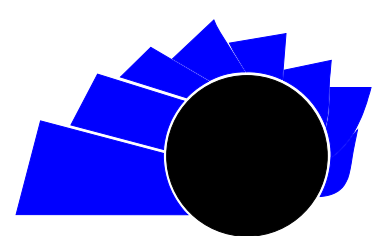

VISIÓN ELECTRÓNICA

\title{
Diagnosis in industrial processes
}

\author{
Diagnóstico de fallos en procesos industriales
}

\section{John William Vásquez Capacho ${ }^{1}$}

INFORMACIÓN DEL ARTÍCULO

\section{Historia del artículo:}

Enviado: 13/08/2017

Recibido: 30/09/2017

Aceptado: 14/11/2017

\section{Keywords:}

Fault diagnosis

Reliability

Risk management

Safety

SIS

Supervision

Open access

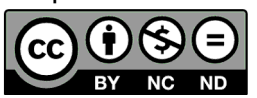

Palabras clave:

Diagnóstico de fallas

Confiabilidad

Gestión de riesgos

Seguridad

SIS

Supervisión

\section{ABSTRACT}

This article describes the most important aspects in the diagnosis of failures on industrial processes. An analysis of process safety is seen from monitoring tools including expert systems as well as intelligent hybrid models. The article continues to identify aspects such as reliability, risk analysis, fault diagnosis techniques and industrial control and safety systems in processes. Reliability and risk analysis provide important information in a process safety tool; analyzes such as HAZOP, FMEA, Fault trees and Bow tie are described through this article. Then compiled and summarized the different techniques and models of fault diagnosis concluding with a presentation of control and safety systems in an industrial process.

\section{RESUMEN}

En este artículo, se describen los aspectos más importantes en la realización de diagnóstico de fallos en procesos industriales. Un análisis de la seguridad en procesos es visto desde las herramientas de supervisión incluyendo los sistemas expertos así como modelos híbridos inteligentes. El articulo continua identificando aspectos como la confiabilidad, análisis de riesgos, técnicas de diagnóstico de fallos y los sistemas industriales de control y seguridad en procesos. La confiabilidad y el análisis de riesgos aportan información importante en una herramienta de seguridad de procesos; análisis como HAZOP, FMEA, Fault trees y Bow tie son descritos en este artículo. Seguidamente se hace un compilado y resumen de las diferentes técnicas y modelos de diagnóstico de fallos concluyendo con una presentación de los sistemas de control y seguridad en un proceso industrial.

\footnotetext{
${ }^{1}$ BSc. In Electronic Engineering, Universidad del Valle, Colombia; and Electronic technology, Unidades Tecnológicas de Santander, Colombia. PhD. In Engineering, Universidad de los Andes, Colombia. PhD. In automatization and industrial engineering, INSA - Universidad de Toulouse, Francia. MSc. In Automattion, Universidad Politécnica de Valencia, España. Esp. In Industrial informatic, Universidad Politécnica de Valencia, España. Current position: Director: Instituto Tecnológico de Bogotá, Colombia. Researcher in Universidad de los Andes, Colombia. Researcher DISCO and LAAS-CNRS groups, Francia. E-mail: director@bitcol.com.co, jw.vasquez10@uniandes.edu.co, jwvasque@laas.fr, jvasquezc@gmail.com.
} 


\section{Introduction}

In automatic control systems the supervision functions serve to indicate undesirable or not permitted processes and states and take appropriate actions that maintain performance and avoid damage or harm conditions. From supervision we can discriminate the following functions:

- Monitoring: The measurable variables are check with respect to their tolerances and alarms that are generated to alert the operators.

- Supervision: Supervision with fault diagnostic: This action is developed from the analysis of the measurable variables detecting the symptoms of a possible failure $[1,2]$.

- Automatic protection: Actions for counteract the possible damages. A system is said to be diagnosable, if whatever the behavior of the system is, we will be able to determine without ambiguity a unique diagnosis.

The diagnosability of a system is generally computed from its model [3], and in applications using model-based diagnosis, such a model is already present and does not need to be built from scratch. The fault diagnosis in general consists on the following three important aspects: Fault detection: it consists in to discover the existence of faults in the most useful units in the process, Fault isolation: it is referred to localize (classified) the different faults, and Fault analysis or identification: it consists into determinate the type, degree and origin of the fault [4]. In Figure 1, is presented the supervision scheme in which the first level involves the instrumentation and actuators of the system. The next level contains the acquisition and control equipments followed by the supervision stage. To determine the events and signals of a procedure is necessary to analyze and to consider the initial conditions of the process and to identify the most possible failure modes. Hence, a complex system requires a division into subsystems for allowing a reliable analysis.

Safety requirements and the increasing efficiency in monitoring, control and management of complex systems motivates great interest and efforts devoted to the development of fault detection and isolation techniques. Many popular approaches are available for identifying faults. Among them, methods based on signals are widely used and try to extract useful information from the analysis of specific signals through a comprehensive and rigorous analysis of the main statistical methods used to detect changes [5].
Figure 1: Supervision squeme.

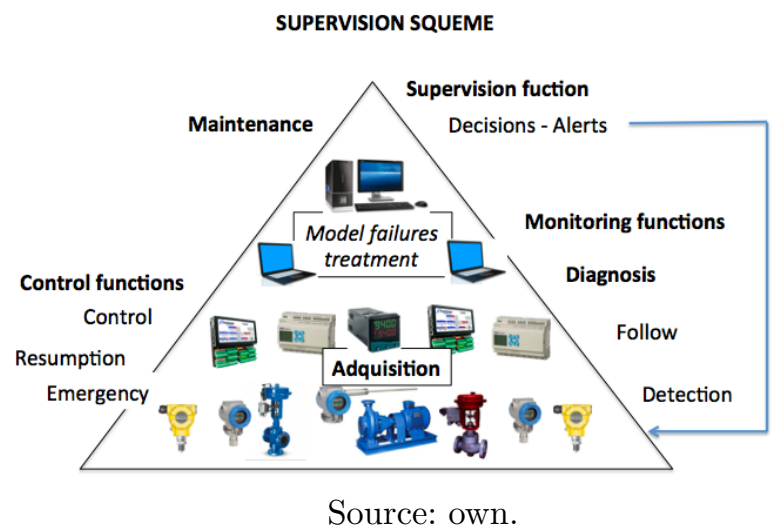

The model-based methods, like parity or space-based approaches observers [6], used a mathematical model of the plant to explore the implicit analytical redundancy relations model to monitor inconsistencies between the model and data measured. However, these methods suggest a big demanding of computational load. Other popular methods as those based on fault trees [7] or causal graphs and propagation [8] were based on a qualitative model of the plant. Other approaches have been developed by expert systems based on artificial intelligence techniques [9].

On the other hand, hierarchical clustering methods were used to carry out pattern matching correlation [10] in which some frequent patterns multiple alarm correlation may be discovered to have the ability to reflect the sequence of normal operation. Any change in the pattern may indicate abnormal alterations sensor degradation or malfunction.

Hybrid intelligent systems are an important future direction to research and to develop in diagnostic systems. The disadvantage of diagnostic systems based on a single method is not versatile enough to control systems on a large scale, so these systems need to integrate various techniques to make efficient diagnosis. The integration of diagnostic methods combines many types of techniques of fault detection; in particular, the complementary combination of quantitative and qualitative models can greatly reduce the false alarm rate. All these methods have their advantages and their specific fields of application, which can be implemented efficiently on a general approach for fault detection in compliance with the following characteristics:

- The modularity and exibility:The model must describe any element of the process and 
environmental assessment. These models should be implemented in a library to use it in the construction of diagnostic algorithm.

- Hierarchical design: According to a top-down approach the model of fault detection could be create diagnostic procedures in different extraction levels.

- Data fusion: The diagnostic system should be able to extract information from many different sources: local signal analysis, intelligent instrumentation, empirical knowledge, logical conditions.

- Temporal Analysis: The diagnostic system can provide useful information to complete the diagnosis analyzing the dynamic events detection in abnormal behavior of the system.

- Compatibility with industry standards: The Failure Mode Effects (FMEA) is a method to determine the possible failure occurrences in the industry. Then, the diagnostic system for the industry must apply this method in the determination of the failures to be detected.

Concluding, the goal to obtain an efficient and reliable methodology in safe process must include the following aspects, see Figure 2: Reliability \& risk management, Control \& safety systems, and Fault diagnosis techniques.

Figure 2: CBAM- Chronicle Based Alarm Management analysis [11-13].

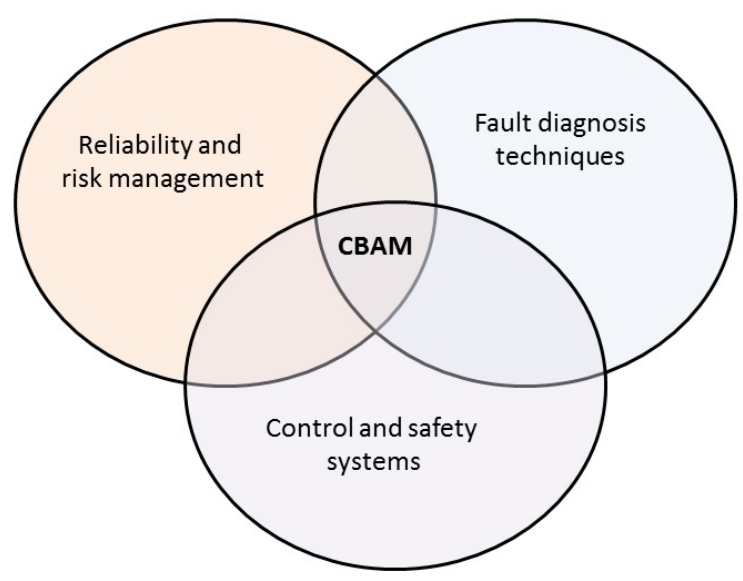

\section{Reliability and risk management}

Reliability can be assumed as the ability of a system or component to perform its required functions under stated conditions for a specified time; meanwhile, safety is the state of being "safe". In other words, it is the condition of being protected from harm or other non-desirable outcomes. Consequently, if a system is reliable, supposedly it is also safe. For example, a new pistol is reliable, but is it safe, so if exists a risk of hurt or damage, the use of a pistol needs strict conditions for its manage. Likewise, it happens in the industrial processes, if there exist the risk of that something wrong occurs, this situation or risk needs management.

Additionally, it is common to confuse safety with security; security is the degree of resistance to, or protection from harm. It applies to any vulnerable or valuable asset, such as a person, dwelling, community, item, nation, or organization. In short, safety is the minimization of a risk of occurrence in accidents and serious incidents in the system, equipments (prevention). On the othne hand, security is responsible for the control of incidents of infrastructure, property and persons against acts of unlawful interference (protection).

The relationship between safety and reliability had been enhanced since the Industrial Revolution. The use of new sources of power, using water or steam, nuclear plants and petro- chemical industry not only have given great potential for the rapid development of manufacturing technology, likewise provided a terrible potential for death and injury when processes went wrong. Due to the demand for new machinery and the use of chemical elements such as oil and gas, the number of fatal accidents has increased. Although, designing new machines make possible the growing scientific knowledge, designers still lean strongly on past experience [14]. On the other hand, based on this experience, some risks can be accepted.

In Figure 3 for example, is represented a framework of the risk assessment process, which contains three levels of activities: Risk analysis, Risk assessment, and Risk management.

Risk analysis is a technical process that initiates defining the system continuing with the hazard identification, frequency analysis, also consequence modeling, and concluding with the risk calculation. The risk assessment level presents the actions of risk acceptability, risk reduction decisions, and cost-benefit judgments. Risk management consists on the action to monitor, test, and control risk levels, and it is part of the safety management plan of the organization.

Quantitative Risk Assessment (QRA) is the most sophisticated technique to calculate the risks of incidents, 
estimate the uncertainties of the calculated risk levels, and provide metrics for cost-effective risk minimization. Moreover, to quantifying the effects of data uncertainty, QRA uses models to estimate conditional probabilities of failure for components or layers of protection that are not mutually independent. For risk assessment related to reactive chemicals, statistical data from incidents are often insufficient and are related to specific circumstances.

Figure 3: Flow diagram for a risk assessment process.

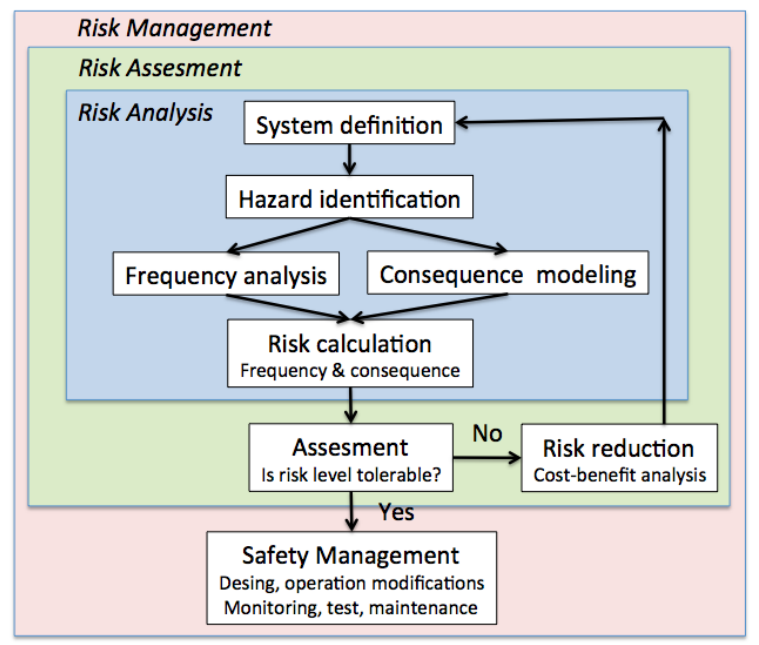

Source: own.

Thus, it is important to develop an effective implementation of QRA methods, such as statistical inference, requires signi cant cost, time and experience. Consequently, less costly qualitative and semi-quantitative risk assessment techniques can be used effectively to identify where a more quantitative analysis of the most critical components of a chemical system may be needed $[15,16]$.

\subsection{Hazard analysis}

A hazard analysis is a systematic method for identifying, evaluating and controlling the hazards of a system. It is part of risk management, which consists in five phases: 1. Definition, 2. Hazard identification 3. Hazard and risk assessment, 4. Proposed hazard resolution, and 5. Follow-up to proposed activities. The analysis of hazards corresponds to the first two phases of this process; however, from the information obtained in these phases, we obtain the necessary information to carry out its evaluation and its proposal of resolution to an acceptable level. These phases are fundamental in processes that undergo modifications, expansions, or a reconfiguration of their operating conditions. Hazard assessment techniques can be classified as: scenario-based or non-scenario-based. Among the first are procedures such as: Hazop, What if?, FMA, fault tree analysis, event tree analysis and cause-consequence analysis (or bowtie). For the second, there are procedures such as: Preliminary Hazard Analysis (PHA), safety review, relative ranking and checklists. Some of these analyzes are brie y explained below.

Hazop provides a systematic way of identifying hazards using a number of guide works as an aid. Just how the words are interpreted depends on the circumstances, but for example 'None of' could lead to a consideration of the possibility of no liquid flow in one case or no electrical current or no pressure in others. Other guide words and some applications are present in Table 1.

Table 1: Hazop table

\begin{tabular}{|l|l|}
\hline Guide words & Description \\
\hline More of & $\begin{array}{l}\text { Liquid flow too high, pressure or electrical } \\
\text { current too high. }\end{array}$ \\
\hline Less of & $\begin{array}{l}\text { Liquid flow too low, temperature, pressure } \\
\text { or electrical curren too low. }\end{array}$ \\
\hline Part of & $\begin{array}{l}\text { Chemical component missing, composition } \\
\text { wrong. }\end{array}$ \\
\hline More than & $\begin{array}{l}\text { Impurities present, extra phase present (gas } \\
\text { in liquid, for example) }\end{array}$ \\
\hline
\end{tabular}

Source: own

In each case the guide word is used to concentrate attention on to one particular fault (no liquid ow, for example). Possible causes of lack of flow are then examined and the effects of it are enumerated. The complete set of guide words is applied in this way to each component or process in turn. The design can be modified to avoid the associated hazards and consequent operational problems. This technique is commonly used in the chemical industry and is particularly effective if applied by a mixed team providing expertise in design, instrumentation, commissioning and operation. Zonal analysis is a method used to examine possible cascade and common mode failures in aircraft.

In this case, the aircraft is sub-divided into zones and for each zone all actuators and other items of equipment within the zone are itemized. The mutual interactions within the zone are then examined as are the interactions with similar devices outside the zone. The interactions may be anything from electrical interference to leakage of hydraulic uids or water, or undesirable mechanical interactions. Both normal and fault conditions are 
considered. As in the case of Hazop, zonal analysis provides a systematic framework for the investigation of a particular type of failure.

Checklist is another tool, which is used to check compliance with standard industrial procedures. Its main objective is to identify simple hazards and ensure compliance with regulations / operational standards. Their evaluation is of qualitative type from the implementation of a checklist, which can be applied in all stages of production. DOW / MOND indexes consists of the identification and classification of risks through the use of performance indexes and the state of the internal processes of the plant or physical characteristic. These indexes are relative and are assigned in a subjective in the form of a bonus or penalty. For the first case, and it includes the characteristics that allow to mitigate the occurrence of an accident, whereas the penalties correspond with situations that can lead to the occurrence of an accident. The results obtained are of semiquantitative type, since they allow a classi cation and realize a subjective assignment of values for its calculation [17].

In Preliminary Hazard Analysis (PHA), the main objective is to identify hazards in the initial stages of industrial plant design. This analysis is directed to the management of hazardous substances associated with the raw material, nished product, and intermediate products.

As a result, a list of possible hazards is obtained with their respective recommenda- tions to prevent / mitigate them. It is a qualitative analysis that strengthens the design of a process plant to make an inherently secure system [17].

Analysis What if? it is an analysis that focuses on the identification of unwanted consequences caused by a possible initiating event; analysis performed by a group of experts. It is a non-formal method, but it has shown to be useful in the definition of potential scenarios, identifying sequences of events leading to the occurrence of the fault. Also, it can be used to examine possible deviations from the design, construction, operation, or modifications to the plant. The result is of qualitative type, corresponding with a list of possible scenarios and the strategy to reduce its possible consequences [17]. Similarly, the "What if?/Checklist is a technique whose purpose is to identify hazards by considering general types of incidents that may occur in a process or activity, qualitatively assessing the effects of the same, and determining when safeguards against of this potential hazard seem appropriate [18].

Fault Mode Analysis (FMA) is a methodology aimed at industrial equipment. Its analysis consists in the evaluation of possible fault mechanisms of each equipment, defining possible fault scenarios and their respective consequences. Its result is qualitative in that it classifies each of the situations obtained according to their consequences [17].

Fault tree analysis (FTA) is a deductive technique that focuses on a particular incident or major cause of failure, and provides a method for determining the causes of such an event.

The purpose of the FTA is to identify the combination of operational type failures, design material or process disturbances that could result in the incident. The strength of this analysis is to identify qualitatively the combinations of basic faults that could lead to the incident. What serves for the hazard analyst to take preventive measures in basic causes to reduce the probability of occurrence of the event (event in safe process is refereed to an accident).

Event Tree Analysis (ETA) is an event tree graphically that shows the possible outcomes following the success or failure of a protection system, given the occurrence of a specific initial cause. It is used to study the possible events that can happen in case there is a loss event. After these sequences of events are identified, the specific combinations of faults that lead to the incident are obtained [18].

Cause-consequence analysis / Bowel analysis: A cause-and-effect analysis is a mixture of a fault and event tree, where its purpose is to identify the root causes and consequences of potential incidents. A particular case of this type of analysis is the one of Bowel, which correlates the existing security barriers, and evaluates their suitability. Subsequently, additional protection and recommendations are determined if necessary. Causal events are presented to the left of the diagram and consequences to the right. An attribute of the Boundary method is that it is a visual form that clearly represents risk.

The selection of the technique to be implemented for the evaluation of hazards follows a process that takes into account the type of information available, the response time of the analysis, the different stages of the life of the process facilities, among others. To carry out the above, there are methodologies that suggest the most appropriate technique to implement as reported by CCPS (Center for Chemical Process Safety) [18]. 


\section{Control and safety systems}

Process control systems had been developed to monitor data and control the variables and equipments on the industrial plant. Slight installations may use electric, hydraulic or pneumatic control systems; however, larger plants with up to 50,000 signals to and from the process require a dedicated distributed control system. The purpose of this system is to read values from a large number of sensors, run programs to monitor the process and control valves, motors, switches etc. to maintain under control the process. Values, alarms, reports and other information are also presented to the operator and command inputs accepted. Nowadays, a modern Process control system basically include of the following components [19]:

- Field instrumentation: sensors and switches that sense process conditions such as temperature, pressure or flow. These are connected over single and multiple pair electrical cables (hardwired) or communication bus systems called fieldbus, modbus, profibus.

- Control devices, such as actuators for valves, electrical switchgear and drives or indicators that can be also hardwired or connected over an industrial net of communications.

- Controllers: Equimpents that execute the control algorithms and desire actions that can be taken. The controllers will also generate events and alarms based on changes of state and alarm conditions and prepare data for operators and information systems.

- Servers that perform the data processing are required for data presentation, historical archiving, and alarm processing including engineering changes.

- Clients such as operator stations and engineering stations are provided for human interfaces. Which means customers can communicate to a human being.

- The communication can be exhibited in many different configurations, often including connections to remote facilities, remote operations support and similar.

The principal activity of the control system is to ensure a safe production, maintaining the components and element working efficiently within design constraints and alarm limits in the different variables. The control system is commonly determined in programs as a mix of logic and control elements such as AND, OR,
NOT, PID, FUZZY. From a Central Control Room (CCR), the system is operated with a combination of graphical process displays, alarm lists, reports and historical data curves. In this platform, new models of fault diagnosis can be implemented, the problem is to validate and to confirm the reliability of this theoretical models of diagnosis. Otherwise, with modern systems, the information in the desk screens is available to remote locations such as an onshore corporate operations support center. Field devices in most process areas must be protected to prevent them becoming ignition sources for potential hydrocarbon leaks. These equipments are explosive hazard classified e.g. as safe by pressurization (Ex.p), safe by explosive proof encapsulation (Ex.d) or intrinsically safe (Ex.i). All areas are mapped into explosive hazard zones from Zone 0 (inside vessels and pipes), Zone 1 (risk of hydrocarbons), Zone 2 (low risk of hydrocarbons) and Safe Area. Beyond the basic functionality, the control system can be used for more advanced control and optimization functions.

\subsection{Safety instrumented systems SIS}

A Safety Instrumented System (SIS) is a new term used in the standards that has also been known by the majority as: Emergency stop system (ESD), System of safety stop, system of interlocks, emergency ring system, security systems, etc. It could also be defined as the ultimate preventive security layer if the control system and operator performance are insufficient. In this case, there must exist a system that automatically takes the appropriate actions (partial or total stops of equipment and plants) in order to avoid the risk. These safety instrumented systems are normally separate and independent from control systems, including logic, sensors and valves on field. Unlike control systems, which are active and dynamic, SIS are basically passive and "sleepy", so they usually require a high degree of safety and fault diagnosis, as well as to prevent inadvertent changes and manipulations and good maintenance [20]. Therefore, to involve fault diagnosis methodologies is one important aspect of safety process that needs to be developed continuously.

When an accident occurs, it is usually due to a number of causes or their combinations that produce a dangerous event. In the industry are implemented the Emergency Stop Systems (ESD) for the protection of humans, the environment and equipment. Therefore, it is not a new concept, the novelty is the way to treat it. In other words, emergency shutdown systems will have a life cycle, which we will call Security Life Cycle. This cycle will begin in its de nition phase and will end in the dismantling. The variety of names assigned to Emergency 
Stop Systems seems unlimited: Interlocking System (IS), Instrumented Security System (SIS), Emergency Stop System (ESD), etc. Within the Process Industry, the debate continues on the meaning of each one of them. Even in the ISA SP84 Committee there were ongoing discussions of the terminology, definition and meaning of each of these terms. Nonetheless, the confusion in the industry goes beyond its own meaning, it affects own design, installation, commissioning, maintenance, modifications, etc. There are many examples and questions that do not are easy to answer or the answer is not the same, depending on the standard or the person who gives it. Some typical doubts are set out as an example:

- Selection of the technology to use

$\sqrt{ }$ What technology should be used: relays, solid state, microprocessor (PLC)?

$\sqrt{ }$ Does that selection depend on the application?

$\sqrt{ }$ Relays are still used in small applications but would you design a system with 500 relay inputs / outputs?

$\sqrt{ }$ Is it economical to design a system of 20 inputs/outputs with redundant PLCs?

$\sqrt{ }$ Some prefer not to use software-based systems in security applications. Is it a good recommendation?

- Selection of redundance

$\sqrt{ }$ How redundant should a safety instrumented system be designed?

$\sqrt{ }$ Does it depend on the technology or the level of risk?

$\sqrt{ }$ If most relay-based systems are simple, why are programmable triple redundancy systems so popular today?

- Field elements

$\sqrt{ }$ Should the initiating elements be transmitter type or switch type?

$\sqrt{ }$ If we use transmitters. Which type, analog or digital?

$\sqrt{ }$ Redundancy or not in the eld elements?

$\sqrt{ }$ Can the same eld elements be used for interlocks and for control?

$\sqrt{ }$ Which is the best frequency of proof of these elements?

\section{Fault diagnosis techniques}

The knowledge that we can acquire about the behavior of a physical system is based primarily on the acquisition and valuation of two types of information: Quantitative, which is acquired through various measuring instruments variables that characterize the system operation. Qualitative, which is acquired by humans through the sensory organs and processed by the brain, usually provided in the form of linguistic information [21, 22]. In fault detection process we cannot neglect any kind of information because both are essential for the generation of fault indicators. This summary of fault detection techniques had been constructed based into two types of procedures: Data driven techniques and Model - based techniques.

\subsection{Data - driven techniques}

In diagnosis theory, there exists promising methods of fault diagnosis in technical systems described by linear and nonlinear models; methods noted as "model-free" or "data-driven" methods $[23,24]$. The basic philosophy of the model-free approach for fault detection and diagnosis is to collect as many measurable information from the process as possible. This means, that only are considered continuous measurements, and a set of measurements of the process by using sensors is represented as a pattern $[25,26]$. A list of the most popular data-driven techniques is presented below.

1. Data - driven techniques

a) Quantitative techniques

I. Statistical $[27,28]$ :

- PCA (Principal Component Analysis), SPC (Statistical process control charts), FDA (Fisher Discriminating Analysis), GDA (Generalized Discriminating Analysis).

II. Neuronal networks (Multivariable models built from a set of I/O data) [29]

b) Qualitative techniques

I. Expert systems (Rule-based feature extraction) [30]:

- Neuronal networks: Pattern classification approach. Fuzzy logic [31, 32]. Genetic algorithm [33]

II. Qualitative trend analysis (Abstraction of trend information):

- Triangulation [34], Finite difference method [35], Syntactic pattern recognition approach [36], Gaussian filter [37]. 


\subsection{Model - based techniques}

Different approaches for fault detection use mathematical and graph models. The mission correspond to the detection of faults in the processes, faults in the actuators and sensors by using the dependencies between different measurable signals. These dependencies are expressed by mathematical process models. The basic structure of a model-based fault detection is based on measured input signals and output signals. The detection methods generate residuals, parameter estimates or state estimates, which are called features. By comparison with the normal features, changes of features are detected, leading to analytical symptoms. A list of the most popular model-based techniques is presented below.

1. Model - based techniques

a) Quantitative techniques

I. Residual generation methods:

- Analytical redundancy [38-40], Residuals and parameterization of residual generators [41], Fault detection filter (Observer) [42]

II. Parity space [43]

III. EKF Kalman lters [44]

b) Qualitative techniques

I. Causal models:

- Diagraph (Graph with directed arcs between the nodes) [45] • Bond graphs [46] • SDG - Signed direct graph [47] • ESDG - Extended SDG [48] • PCEG - Possible cause and effect graph models $[49,50]$ • HDG - HAZOP-digraph models [51] • SCC Strongly Connected Component [52] • MSCC - Maximal strongly connected component [53]

- Causal Graphs [54] • Chronicles [13,55,56]

- Fault trees [57]

II. Qualitative physics:

- Qualitative behavior from the ordinary differential equations (ODEs), Qualitative differential equations (QDEs) [58], QSIM (Qualitative simulation) [58]

III. Abstraction hierarchy

- Structural [59] - Multilevel Flow Models (MFM) • Functional [60]

As the alarms and the procedural actions in an industrial process are assumed as discrete events, the model-based technique used in the methodology (CBAM) are the Chronicles.

\section{Conclusions}

In this paper was presented an analysis of the diagnosis in industrial processes in which reliability and risk management were studied including the intrinsic safety and the identication of the hazards. In addition, it was considered the control and safety systems with the description of the Safety Instrumented Systems SIS. By concluding with the different fault diagnosis techniques were exposed, taking into account the data-driven and model-based techniques.

\section{References}

[1] A. Astolfi, L. Praly, "Global complete observability and output- to-state stability imply the existence of a globally convergent observer". Mathematics of Control Signals and Systems, vol: 18, pp. 32-65, 2006.

[2] J. Lew, J. Juang, H. Keel, "Quantification of parametric uncertainty via an interval model", Journal of Guidance Control and Dynamics, vol 17, no. 6, 1994, https://doi.org/10.2514/3.21335

[3] M. Bayoudh, L. Travé-Massuyès, X. Olive, "Hybrid systems diagnosability by abstracting faulty continuous dynamics". Proc. of the 17th International Workshop on Principles of Diagnosis, pp. 915, 2006.

[4] S. Ding, "Model-based fault diagnosis techniques design schemes, algorithms, and tools", Springer, 2008 .

[5] L. Magni, R. Scattolini, C. Rossi, "A fault detection and isolation method for complex industrial systems", IEEE Transactions on Systems, Man, and Cybernetics - Part A: Systems and Humans, vol 30, november 2000, https://doi.org/10.1109/3468. 895922

[6] R. J. Patton, J. Chen, "Observer-based fault detection and isolation: robustness and applications", Control Engineering Practice, vol. 5, no. 5, pp. 671-682, https://doi.org/10.1016/ S0967-0661 (97) 00049-X

[7] R. Vries, "An automated methodology for generating a fault tree", IEEE Transactions on Reliability, 1990, https://doi.org/10.1109/24.52615

[8] F. Yang, D. Xiao, "Progress in root cause and fault propagation analysis of large scale industrial processes", Journal of Control Science and Engineering, 2012, https://doi.org/10.1155/ $2012 / 478373$ 
[9] H. Sarmiento, C. Isaza, "Identification and estimation of functional states in drinking water plant based on fuzzy clustering", 22st European Symposium on Computer Aided Process Engineering. pp. 1317 to 1327, https://doi.org/10.1016/ B978-0-444-59520-1.50122-6

[10] Y. Chen, J. Lee, "Autonomous mining for alarm correlation patterns based on time-shift similarity clustering in manufacturing system". IEEE International Conference on Prognostics and Health Management, 2011.

[11] J. Vásquez, J. Prada, C. Agudelo, F. Jimenez, "Analysis of alarm man agement in startups and shutdowns for oil re ning processes", IEEE Explorer Engineering Mechatronics and Automation International Congress, Bogota, 2013.

[12] J. Vásquez, L. Travé-Massuyès, A. Subias, F. Jimenez, C. Agudelo, "Chronicle based alarm management in startup and shutdown stages", International Work-shop on Principles of Diagnosis, 2015 .

[13] J. Vásquez, L. Travé-Massuyès, A. Subias, F. Jimenez, C. Agudelo, "Alarm management based on diagnosis". 4th IFAC International Conference on Intelligent Control and Automation Sciences, 2016, https://doi.org/10.1016/j.ifacol.2016. 07.101

[14] S. Cox, R. Tait, "Reliability, Safety, and Risk Management". John Wiley \& Sons, Ltd, 2008, https : //doi.org/10.1002/9780470061572.eqr360

[15] J. Tixier, G. Dusserre, O. Salvi, D. Gaston, "Review of 62 risk analysis methodologies of industrial plants". Journal of loss prevention in the process industries, vol 15, issue 4, 2002, https://doi.org/ $10.1016 / \mathrm{S} 0950-4230(02) 00008-6$

[16] C. Wei, W. Rogers, M. Mannan, "Layer of protection analysis for reactive chemical risk assessment", Journal of hazardous materials, vol 159, issue 1, November 2008, https://doi.org/10. 1016/j.jhazmat.2008.06.105

[17] M. Sánchez, "Introducción a la con confiabilidad y evaluación de riesgos", Bogotá: Universidad de los andes, segunda edióion, 2010.

[18] CCPS, "Guidelines for Hazard Evaluation Procedures", New York: Wiley. Wiley, 2008.

[19] H. Devold, "Oil and Gas Production Handbook: An Introduction to Oil and Gas Production", SRH Media, 2013.
[20] I. Fernández, A. Camacho, C. Gasco, A. Macias, M. A. Martin, G. Reyes, "Seguridad funcional en instalaciones de proceso: sistemas, instrumentados de seguridad y análisis SIL", Ediciones Díaz de Santos, S.A, 2012.

[21] A. Shui, W. Chen, P. Zhang, S. Hu, X. Huang, "Review of fault diagnosis in control systems", IEEE, 2009 .

[22] V. Venkatasubramanian, R. Rengaswamy, K. Yin, S. N. Kavuri, "A review of process fault detection and diagnosis", Computers and Chemical Engineering, vol 27, issue 3, 2003.

[23] A. Bittencourt, K. Saarinen, S. Sander-Tavallaey, "A data-driven method for monitoring systems that operate repetitively - applications to wear monitoring in an industrial robot joint", 8th IFAC Symp, 2012.

[24] S. Ding, Y. Wang, S. Yin, P. Zhang, Y. Yang, E. Ding, "Date-driven design of fault-tolerant control systems". Proc. 8th IFAC Symp, 2012.

[25] A. Shumsky, "Data driven method for fault detection and isolation in nonlinear uncertain systems", Proc. IFAC Conf. on Control Applications in Marine Systems, 2007, https://doi.org/10. 3182/20070919-3-HR-3904.00050

[26] A. Zhirabok, S. Pavlov, "Data-driven method of fault detection in technical systems", 25th DAAAM International Symposium on Intelligent Manufacturing and Automation, 2014.

[27] P. Nomikos, J. MacGregor, "Monitoring batch processes using multiway principal component analysis". American Institute of Chemical Engineers Journal, vol 40, issue 8, 1994.

[28] Z. Wang, C. Zhu, Z. Niu, D. Gao, X. Feng, "Monitoring batch processes using multiway principal component analysis", Knowledge-Based Systems, 2014.

[29] V. Venkatasubramanian, R. Vaidyanathan, Y. Yamamoto, "Process fault detection and diagnosis using neural networks part i: Steady state processes", Computers and Chemical Engineering, vol 14, issue 7, 1991.

[30] R. Rengaswamy, V. Venkatasubramanian, "A fast training neural network and its updation for incipient fault detection and diagnosis". Computers and Chemical Engineering, vol 24, issues 2-7, 2000, https://doi.org/10.1016/S0098-1354(00) 00434-8 
[31] E. Garcia, C. Agudelo, F. Morant, "Secuencias de alarmas para detección y diagnóstico de fallos", 3er Congreso internacional de ingeniería mecatrónica, 2012.

[32] S. Dash, R. Rengaswamy, V. Venkatasubramanian, "Fuzzy-logic based trend classi cation for fault diagnosis of chemical processes". Computers \& Chemical Engineering, vol 27, issue 3, 2003.

[33] M. Unal, M. Onat, M. Demetgul, H. Kucuk, "Fault diagnosis of rolling bearings using a genetic algorithm optimized neural network". Measurement, vol 58, 2014.

[34] J. Cheung, G. Stephanopoulos, "Representation of process trends part i: A formal representation framework", Computers \&3 Chemical Engineering, vol 14, issue 4-5, pp. 495-510, 1990, https://doi.org/ 10.1016/0098-1354(90)87023-I

[35] M. Janusz, V. Venkatasubramanian, "Automatic generation of qualitative descriptions of process trends for fault detection and diagnosis". Engineering Applications of Artificial Intelligence, vol 4, issue 5, pp. 329 - 339, 1991, https://doi.org/10.1016/ 0952-1976 (91) 90001-M

[36] R. Rengaswamy, V. Venkatasubramanian, "A syntactic pattern-recognition approach for process monitoring and fault diagnosis". Engineering Applications of Artificial Intelligence, vol 8, issue 1, pp. 35 - 51, 1995, https: //doi.org/10.1016/0952-1976(94)00058-U

[37] J. Yu, "A particle filter driven dynamic gaussian mixture model approach for complex process monitoring and fault diagnosis", Journal of Process Control, vol 22, issue 4, 2012, https://doi.org/10. 1016/j.jprocont.2012.02.012

[38] M. Basseville, "Detecting changes in signals and systems: a survey". Automatica, vol 14, issue 3, 1988, https://doi.org/10.1016/0005-1098(88) 90073-8

[39] E. Chow, A. Willsky, "Analytical redundancy and the design of robust failure detection systems". IEEE Transactions on Automatic Control, pp.603-614, 1984, https://doi.org/10.1109/TAC.1984. 1103593

[40] P. M. Frank, "Fault diagnosis in dynamic systems using analytical and knowledge- based redundancy a survey and some new results". Automatica, vol. 26, no. 3, pp. 459-474, 1990, https://doi.org/10. 1016/0005-1098(90) 90018-D
[41] P. Frank, X. Ding, "Survey of robust residual generation and evaluation methods in observer-based fault detection systems". Journal of Process Control, vol 7, issue 6, pp. 403 - 424, 1997, https ://doi .org/ 10.1016/S0959-1524(97)00016-4

[42] J. Chen, R. Patton, "Robust model-based fault diagnosis for dynamic systems", Massachusetts: Kluwer Academic Publishers, 1999, https://doi. org/10.1007/978-1-4615-5149-2

[43] M. Desai, A. Ray, "A fault detection and isolation methodology-theory and application", Proceedings of American control conference, pp. 262-270, 1984.

[44] A. Willsky, "A survey of design methods for failure detection in dynamic systems". Automatica, vol 12, issue 6, pp.601-611, 1976, https://doi.org/10. 1016/0005-1098 (76) 90041-8

[45] M. Maurya, R. Rengaswamy, V. Venkatasubramanian, "A signed di- rected graph and qualitative trend analysis-based framework for incipient fault diagnosis". Chemical Engineering Research and Design, vol. 85, no.10, 2007, https: //doi.org/10.1016/S0263-8762(07)73181-7

[46] A. Samantaray, K. Medjaher, B. Ould-Bouamama, M. Staroswiecki, G. Dauphin- Tanguy, "Diagnostic bond graphs for online fault detection and isolation", Simulation Modelling Practice and Theory, pp. 237 - 262, 2006, https://doi.org/10.1016/j.simpat. 2005.05 .003

[47] . Yang, D. Xiao, L. Shah, "Qualitative fault detection and hazard analysis based on signed directed graphs for large-scale complex systems", Tsinghua University, University of Alberta China, 2010 .

[48] Y. Liu, G. Xie, Y. Yang, Z. Chen, Q. Chai, "Hierarchical method of fault diagnosis based on extended", Control and Decision Conference (2014 CCDC), The 26th Chinese, pp. 3808-3812, 2014, https://doi.org/10.1109/CCDC. 2014.6852843

[49] N. Wilcox, D. Himmelblau, "Possible cause and effect graphs (pceg) model for fault diagnosis i. methodology", Computers and Chemical Engineering, vol 18, issue 2, pp.103 - 116, 1994, https://doi.org/10.1016/0098-1354(94) 80131-2

[50] M. Kramer, P. L. Palowitch, "A Rule-Based Approach to Fault Diagnosis Using the Signed Directed Graph", AIChE Journal, vol. 33, no. 7, pp. 1067 - 1078, July 1987, https://doi.org/10.1002/ aic. 690330703 
[51] R. Vaidhyanathan, V. Venkatasubramanian, "Digraph-based models for automated hazop analysis", Reliability Engineering and Systems Safety, vol 50, issue 1, pp.33 - 49, 1995, https: //doi.org/10.1016/0951-8320(95)00052-4

[52] M. Kramer, J. B. Palowitch, "A rule-based approach to fault diagnosis using the signed directed graph", AIChE Journal, vol 33, issue 7, pp.1067-1078, 1987, https://doi.org/10.1002/aic. 690330703

[53] O. Oyeleye, M. Kramer, "Qualitative simulation of chemical process systems: steady state analysis", AIChE Journal, vol 34, issue 9, pp. 1441- 1454, 1988, https://doi.org/10.1002/aic.690340906

[54] B. Celse, S. Cauvin, B. Heim, S. Gentil, L. Travé-Massuyés, "Model based diagnostic module for a fcc pilot plant. Oil \& Gas Science and Technology", revista IFP, vol. 60, no. 4, pp. 661-67, 2005.

[55] C. Dousson, "Suivi d'é volution et reconnaissance de chroniques". Thése de doctorat, Université Paul Sabatier, 1994.
[56] A. Subias, L. Travé-Massuyés, E. LeCorronc, "Learning chronicles signing multiple scenario instances", FAC World Congress, 2014, https:// doi .org/10.3182/20140824-6-ZA-1003.02579

[57] N. Ulerich, G. Powers, "Online hazard aversion and fault diagnosis in chemical processes: the digraph fault tree", IEEE Transactions on Reliability, pp. 171-177, 1988, https://doi.org/10.1109/24.3738

[58] B. Kuipers, "Qualitative simulation", Artificial Intelligence, vol 29, issue 3, pp. 289-338, 1986, https : //doi.org/10.1016/0004-3702(86)90073-1

[59] J. Rasmussen, "The role of hierarchical knowledge representation in decision making and system management". IEEE Transactions on Systems, Man and Cybernetics, pp. 234 - 243, 1985, https://doi. org/10.1109/TSMC. 1985.6313353

[60] F. Finch, M. Kramer, "Narrowing diagnostic focus using functional decomposition", American Institute of Chemical Engineers Journal, vol 34, issue 1, pp.130 - 140, 1987. 